\title{
When English Meets Chinese in Tibetan Schools: Towards an Understanding of Multilingual Education in Tibet
}

\section{ZhiMin Xiao and Steve Higgins}

\begin{abstract}
By tracing the evolution of linguistic models for state education in the Tibet Autonomous Region (TAR) of China, this chapter shows that bilingual education policies in the TAR oscillated between Chinese-led and Tibetan-led models since the 1950s. By presenting the rise and fall of specific linguistic models under a social and historical light, the study demonstrates that Tibetan students' underperformance in subjects like English and Maths today is historically given and economically driven. In other words, the educational landscape as we see in Tibet today is socially constructed and represents competing interests of different groups. With English added to the mix, the complexity of language education policies in the TAR has increased. Upon interviewing students of diverse socioeconomic backgrounds from across the TAR and looking into their past and present schooling experiences, the authors argue that the dynamics between linguistic models and linguistic capital in the TAR articulate ethnic sentiments, leadership preferences, and the myriad ways in which Tibetans responded to the authority exercised by the leadership.
\end{abstract}

\section{Keywords}

Chinese, English, Language Policy, Tibetan, Trilingualism

\section{Introduction}

"English, there is no way, I think, for me to learn it well. I don't know why. Even though I attended additional private tutorial courses during summer and winter vacations, it simply didn't work ... for me, English is no longer a possibility. I think Mandarin is now the most important, because most people speak it, so I will do my best to learn it well. But English, no matter how hard I study, I just can't get it. Every English class is too long for me to survive. Anyway, we Tibetans don't use English that much. We use Mandarin to communicate with people from different ethnic backgrounds. English is spoken in classrooms only ... [But] for a 
Key class like ours, ${ }^{1}$ the average score in English is a little more than 20 or 30 [out of 150], like what we usually get in Mathematics" (Diki). ${ }^{2}$

This interview excerpt reveals how one Tibetan student from a relatively affluent family bemoaned her poor performance in English when ZhiMin, the first author of this chapter, spent three and a half weeks in the Tibet Autonomous Region (TAR) in early 2011. During his stay in School Basum, located in Town Bami, which is about 350 kilometers away from Lhasa, he was struck by the frustrations students and teachers encountered in their learning and teaching of English - it was not just the student above who faced challenging demands, many other students interviewed in this study reported similar experiences. Importantly it was not only students, who sometimes expressed their loss of hope in learning English; the teachers also experienced similar difficulties and obstacles, in making themselves understood, despite the fact that Basum is a key school in the TAR. How can we account for this problem in Tibetan schools then? To date, considerable debate has centred on linguistic issues in education. Which language should be used as the medium of instruction? If it is Tibetan, how can students reach competence in Mandarin as the lingua franca in China? If it is Chinese, what measures should be taken to ensure that students learn by efficient and effective means, while Tibetan culture and ethnic identity are respected and preserved at the same time? When and how should Chinese as the medium of instruction be introduced? When English is added as a third language that Tibetans must learn as early as year 1 in primary schools today, ${ }^{3}$ what impacts does it have on learning and teaching in Tibetan schools? How should policy makers of minority education strike a balance between development vs. stability and consistency vs. continuity? It is evident that policies related to bilingual education in Tibet since the 1950s have oscillated between Chinese-led and Tibetan-led models - they primarily depended on the leadership and the way in which Tibetans responded to the authority exercised by the leadership (Bass, 1998; Ma, 2011; Zenz, 2010). Indeed, education can have many competing aims, and the balance between the retrospective value of understanding one's past culture, history, and linguistic tradition must be weighed against the prospective value of equipping learners for the world they will inherit (White, 1982). Where there is no shared view of the past, nor a shared vision for the future, it is not surprising that these aims come into more problematic conflict (Badengnima, 2001, pp. 95-96; Johnson, 2000).

To better understand and then address the problems related to minority education in general, important empirical research has been conducted in several regions of China (Adamson \& Feng, 2009; Cobbey, 2007; Feng \& Sunuodula, 2009; Huang, 2007; Wan \& Zhang, 2007). However, little has been attempted to understand trilingual education in the TAR as a social and educational phenomenon, that is, to borrow a few words from Farmer (2005, p. 9), "historically given, economically driven," culturally shaped, and politically structured. And yet, Tibetans have been persistently labelled as underachievers in education (Barnett, 2008; Hannum, 2003; Zhu,

\footnotetext{
${ }^{1}$ High schools throughout China usually divide their classes into Arts and Science tracks, within which Key and Ordinary classes are categorised according to their students' attainment in their studies.

${ }^{2}$ While the data reported in this chapter accurately communicate the spirit of our work as researchers, all names and identifying information in the study, except for those of the authors, have been altered.

${ }^{3}$ In this study, all interviewees, 16 in total, started learning Mandarin at year 1 and English at either year 1 (Karma), year 2 (Diki), 3 (Champo), or 4 (Cetan, Zenji) of primary school.
} 
2008), despite the fact that substantial financial investment from the central government (Liao, 2008) and culturally specific educational policies (or "preferential policies" as they are termed in China) have been made and promulgated to ameliorate the educational situation in the TAR. Moreover, as Chen and Postiglione (2009) note, Tibet is of great concern to the state, not just because of its geographical size and abundance of natural resources, but also because Tibetans are among the most religious minority groups in China, which often causes state schooling in the TAR to be a highly contentious topic. Although the living standards of many Tibetans have steadily improved (Goldstein, Childs, \& Puchung Wangdui, 2010; Goldstein, Jiao, Beall, \& Tsering, 2003; Steel, Alton, Wyatt, \& Gray, 2009), political tensions continue to be a part of their lives. ${ }^{4}$ Therefore, evidence-based empirical research in the TAR is likely to help and assist China to improve the situation in Tibet, by making it "more economically prosperous, culturally visible, nationally integrated, and politically secure" (Postiglione, 2008, p. 4). We hope the findings and analyses presented in this chapter will contribute towards that aim. But, at the outset, it is necessary to review in what way multilingual education in the TAR has evolved, for history can, as Jeremy Greene suggested, help us "defamiliarize the present and provide critical distance on current practices, and the rupture between past practices and present situations offer key insights into the process of meaningful social change" (personal communication, September $24^{\text {th }}$, 2013).

\section{From Two to Three in Tibet: Languages in Minority Education}

The provision and quality of education in Tibet have improved significantly since 1959 (Badengnima, 2009, p. 51), however, official statistics in the earlier days, rarely collected or revealed linguistic data (Ma, 2011, p. 4). In Tibet, a fundamental issue in education today is not about whether Chinese should be learned or not learned, but about when and to what extent should Chinese be promoted (p. 7). The section which follows will explain why this is no longer an either-or question, by tracing the history of education in Tibet.

In November 1961, the then Tibet Work Committee required all community-run primary schools to offer Tibetan, Arithmetic, and Politics. In these schools, Tibetan was the medium of instruction and all textbooks were produced in Tibetan. Chinese was introduced according to school circumstances and the level of acceptance by the local populace (Zhang, 2007, p. 14, cited in Ma, 2011). Meanwhile, state-run schools were instructed to add Chinese from year 3, but Tibetan remained the primary medium of instruction (Badengnima, 2009, p. 51). However, there slowly emerged Chinese-medium schools in urban areas, where Mandarin was the primary language of instruction and Tibetan was taught from year 3 (Ma, 2011, pp. 8-9). It is worth noting that in this period, it was not just Tibetan teachers who were encouraged to learn Mandarin, but Han Chinese teachers in Tibet were required to learn Tibetan too. This was deemed necessary to teach in Tibetan schools (Zenz, 2010, p. 301). However, as students progressed onto the secondary level, schools encountered greater challenges, whilst attempting to teach higher-grade science subjects in Tibetan. In other words, Tibetan-medium schools had to confront the shortage of bilingual teachers and lack of textbooks in Tibetan, even though the

\footnotetext{
${ }^{4}$ In framing the situation in Tibet, we try not to problematise the issue in question. But ZhiMin's experience in the TAR enabled us to write it that way. For instance, when he took a photo of a school there, somebody immediately came out and questioned him about his intention. This was not a problem at all when he visited other schools in inland provinces of Hunan and Guangdong.
} 
government's basic policy of adopting Tibetan as the primary language of instruction remained unchanged.

The second phase featured the Cultural Revolution (1966-1976), a countrywide campaign aiming to eliminate the "four olds" (old culture, old customs, old ideas, and old habits) and to advance to socialism (though only culturally and spiritually, given the level of economic development at that time). In this period, the Tibetan language was associated with Tibet's old custom of slavery in society and was subject to crude attacks (see Goldstein, 1997, pp. 59-60 for an account of the Revolution), as were countless teachers (Badengnima, 2001, p. 93), leading to schools in the TAR remaining closed for years (Badengnima, 2009, p. 51; Bass, 1998). Although many schools gradually re-opened in the 1970s, the Tibetan language was judged under-developed and impractical for a long time. The policy which was established at that point, demanded that students learn Chinese from year 1 of the primary level and that first and foremost, their Chinese should be improved (Ma, 2011, p. 9). Another point worth noting, during this period, is that learning was limited to Mao's thoughts, for earlier textbooks were associated with feudalism, capitalism, or revisionism, which were anti-revolutionary and anti-socialist. Therefore, they had to be attacked and abandoned. Like elsewhere in China that time, Mao's Little Red Book ${ }^{5}$ was used as the correct and precise textbook in many schools (Zhang, 2007, p. 43, cited in Ma, 2011). However, in 1974 Mao did call upon the Han Chinese in Tibet to learn Tibetan and in turn, the Tibetans to learn Chinese. Subsequently, schools frequently taught both Tibetan and Chinese, although the year group in which Chinese was introduced, varied from year 3 to 5 at the primary level (Badengnima, 2001, pp. 93-94; Zhang, 2007, pp. 36-37, cited in Ma, 2011).

Following the Cultural Revolution, the central government adjusted its system of governance in Tibet and appointed local aristocratic leaders to various institutions. These individuals in due course, endeavoured to promote Tibetan language and culture. In 1980, the government required students of all ethnic backgrounds in Tibet to learn Tibetan and at that juncture, advocated a system in which Tibetan was declared the primary medium of instruction (Ma, 2011, p. 11). This period, thus, witnessed a process of what Zenz referred to as "Tibetanisation" (2010, p. 295) in Tibetan schools. However, at this point in time very few students actually progressed onto secondary level. In 1987, 99\% of graduates from 2,250 Tibetan-medium primary schools were compelled to spend a preparatory year for junior secondary education in forty middle schools (Ma, 2011, p. 10), where the language of instruction was primarily Chinese. For those who did enter secondary level after the foundation year, it proved to be a very difficult task for them to understand and appreciate some subjects taught in Chinese, particularly science. Therefore, the disjuncture between primary and secondary levels posed a formidable obstacle for the progress towards a largely Tibetan-medium education.

In response to the above challenges, diverse opinions emerged in the late 1980s. Some argued that the state should create opportunities and thereby, enable Tibetan students to learn in Tibetan at all levels. Yet others suggested the legalisation of a Tibetan-led model. However, some Tibetan cadres in cities such as Lhasa contended otherwise. They reasoned that it was important to maintain a dual system, where people could choose between Tibetan and Chinese-medium schools. These factions also emphasised that students learned better when Chinese was the primary medium of instruction, and that students from Chinese-medium schools benefitted and

\footnotetext{
${ }^{5}$ Quotations of Mao's thoughts, compiled by his Defence Minister Lin Biao
} 
experienced additional opportunities for higher education in inland China (Badengnima, 2001, p. 95). Also knowing Chinese was an added advantage in their interactions between the TAR and inland provinces (Ma, 2011, p. 11). This view was contrary to the widely held belief that Tibetans learned better in their native language (Bass, 1998, pp. 237-238). In any case, these differing opinions reflected the challenges in striking a balance between the two languages. However, in 1987, all parties ostensibly agreed that Tibetan should be the primary medium of instruction; Chinese could be introduced at higher grades only if it had no negative impact on learning and teaching in Tibetan. Beyond primary level, Tibetan continued to be the primary medium of instruction with Chinese also being learned, and if conditions permitted, the addition of a third language was allowed. This Tibetan-led model was reinforced by a later regulation, which specified that starting from 1993, most middle school subjects, except for Chinese and foreign languages, should be taught in Tibetan; from 1997 onwards, the model should apply to all high schools; and from the year 2000 onwards, higher education institutions in Tibet should gradually adopt the model (Ma, 2011, p. 12).

Nevertheless, in the 1980s, there were Chinese-medium schools in the TAR, wherein Chinese was the primary medium of instruction, and Tibetan was introduced as an additional language in year 3. These schools were mainly for children of Han Chinese cadres in Tibet, and the separation between Tibetan and Chinese-medium schools was very strict. According to Ma, the policy did not allow the Chinese schools to accept Tibetan students who wanted Chinese instruction. Consequently, the implementation of the Tibetan-led model encountered certain hurdles, particularly in towns and cities (Badengnima, 2001, p. 96), where many Tibetan families preferred to have their children educated in Chinese-medium schools, or ideally in inland Tibetan schools, ${ }^{6}$ even though some groups publicly stressed the significance of establishing a Tibetanled system across all levels (Ma, 2011, pp. 13-14).

In many schools, Chinese was once again accorded increasing influence and authority. Chinesemedium schools stopped offering Tibetan in 1994, suggesting Han Chinese students were no longer required to learn Tibetan in Tibet. Meanwhile, the government advocated a bilingual model, in which a degree of importance was attached to Tibetan, and students were expected to achieve proficiency in both Tibetan and Chinese (zang han jian tong), and some schools were even encouraged to offer a third language, in order to meet the demands of an expanding market economy (W. Zhou, 2003, p. 111). By the year 2000, although over 95\% of all primary schools still adhered to the Tibetan-led model (Zhang, 2007, p. 29, cited in Ma, 2011), most schools beyond that level adopted the Chinese-led model, where most subjects were taught in Chinese and Tibetan was a compulsory subject. It is worth mentioning that the TAR's Education Committee emphasised in 1999, that no single model should dominate all schools, for conditions in different areas varied substantially. The Committee encouraged local schools to experiment and adopt a model (or models) that best fitted their unique circumstances (Ma, 2011, p. 17). However, the People's Congress in the TAR directed that Tibetan and Chinese be the basic instruction languages in compulsory education and a third language be added accordingly (W. Zhou \& Gesang Jiancun, 2004), which amended the 1987 policy that Tibetan be the primary medium of instruction.

\footnotetext{
${ }^{6}$ From 1985 to 2006, over 30,000 Tibetan students studied in inland schools (Ma, 2011, pp. 13-14).
} 
As greater prominence was attached to Chinese, fortunately, the number of Tibetan teachers who could teach in both Tibetan and Chinese also rose, partially due to the return of inland-educated Tibetans. However, there were more Tibetan teachers at lower levels of schooling than at higher levels. For instance, Tibetan teachers of Mathematics constituted less than $30 \%$ of all Maths teachers at senior secondary level in 2005, whereas the percentage in middle schools was over $57 \%$ (Ma, 2011, p. 18). From 2001, all primary schools in urban areas of Tibet began to teach Chinese from year 1 (Zhang, 2007, p. 40, cited in Ma, 2011), and some schools offered English from year 3 (Lu, 2005). The consequence of this action was that in many primary schools, most subjects were taught in Tibetan (except for Chinese and Mathematics in some cases), but in middle schools, most subjects were taught in Chinese, except for Tibetan ( $\mathrm{Lu}, 2005$, pp. 232-233), and very few high schools had Tibetan as the primary medium of instruction (Badengnima, 2009, $\mathrm{p}$. 52). This implied that some students were compulsorily subjected to an abrupt shift from a Tibetan-led model at primary level to a Chinese-led model at secondary level. This shift probably accounted as one of the reasons for the student's low achievement levels in English proficiency tests as exemplified at the beginning of this chapter.

Nonetheless, this period revealed greater flexibility in the fraternisation and socialisation of students from different ethnic backgrounds than had been allowed by the policy sanctioned in the 1980s. According to Qulina (cited in Ma, 2011, p. 19), there were Chinese and Tibetan-medium classes in Lhasa No. 1 Middle School, and students were free to select either stream for junior secondary education. In Lhasa No. 6 Middle School, bilingual teachers gradually reduced the use of Tibetan in higher grades and students' performance improved each year. But the decline of students' competence in Tibetan also concerned numerous sections of society - they began to doubt if the aim of bilingual education (shuangyu jiaoyu) would eventually lead to proficiency in both languages, particularly after Qinghai Province's announcement of Education Outline for 2010-2020, which aimed to move towards a Chinese-let model by 2015. Although some middle schools in the TAR were still demanding a "pure Tibetan" model (Zenz, 2010, p. 301) with all subjects taught in Tibetan, except for Chinese and English, such a model would eventually lead to students being highly competent in Tibetan, but barely proficient in Chinese (p. 302), and ultimately experiencing disappointment in job markets (Badengnima, 2001, pp. 95-96).

Two social theories can help explain the oscillation of linguistic models in Tibet. The first is "the social construction" model advocated by Berger and Luckmann (1967). The theory maintains that the social world is first a product of human work, which is often interpreted as a reality in the process of socialisation. The "objectivated" world then exerts its influences on how individuals behave in specific social contexts (pp. 82-83). The construction of the social world, the authors argued, partly results from the making of institutions, where people typify actions and attach meanings to them, so as to predict and control behaviours of others and/or their own (p. 74). When a new generation is socialised into this constructed world, particularly through the use of its language or narratives, the constructed reality functions as if it were an independent reality, which influences not only the new generation, but also those who constructed the social world in the first place (p. 79).

The educational landscape in Tibet can be understood as a constructed reality, which involves "reciprocal typification of habitualized actions" (Berger \& Luckmann, 1967, p. 72) by all relevant actors. However, the institutions established as a result of the reciprocal interpretations are not subject to any reading by any members of the society. There are legitimate ways of 
reading those linguistic models, and the interpretations must be "consistent and comprehensive in terms of the institutional order, if they are to carry conviction to the new generation" (p. 62), suggesting that any deviations from the legitimised ways of organising the TAR's social and political lives are likely to be viewed as inappropriate or even dangerous, and their actors are subject to sanctions or reactions. This theory thus acknowledges the macro socio-political structure, within which any linguistic model situates. It does not only realise that the educational reality in Tibet is a product of human actions and represents diverse interests of different groups, but it also emphasises that the socio-politically constructed landscape in education has impacts on how students learn and teachers teach. This links to the second theory called "the unanticipated consequences of purposive social action" (Merton, 1936).

By purposive action, Merton (1936) meant human behaviours that involve motives and choices between alternatives (p. 895). The design and implementation of competing linguistic models in Tibet are purposive social actions, which have intended and unintended consequences for education, and other aspects of daily lives in the TAR, such as career prospects of Tibetans in the market economy. According to Merton (1936), social actions do not always have clear purposes, nor do purposive actions imply "rational" actions (p. 896). It follows that purposive actions do not necessarily bring about desired outcomes, nor those which are necessarily desirable. For instance, the desired outcomes to China may not be desirable for all Tibetans. Unanticipated and undesirable consequences often occur due to numerous forces, among which, according to Merton (1936), are the "lack of adequate knowledge, ignorance and error, and imperious immediacy of interest” (pp. 899-902).

In designing an optimal policy for education in Tibet, knowledge is not always evenly distributed among all stakeholders. Even the state at various points in history struggled in finding the "best" model. Even if "scientific knowledge" is available, policy makers and interest groups are equally inclined to act on "opinions and estimates" (Merton, 1936, p. 900). In addition, we often assume that actions that had desired and desirable outcomes in the past and elsewhere would continue to be so "under any and all conditions" (p. 901, original italics). Policy makers in China have been extremely successful in testing their ideas on a small scale prior to applying them more widely. Multilingual models that have proved successful in other countries may not work (well) in Tibet either. Moreover, the current imperious immediacy of interest in Tibet, as analysed earlier, is political stability and ethnic unity, which means, any linguistic model, however scientifically sound it may be, must function in a socio-politically stable environment that is friendly to educational experimentation.

\section{Linguistic Capital and Multilingual Models}

Having traced the evolution of linguistic models in Tibet, we will examine the relationship between those models and linguistic capital in this section. According to Bourdieu (1977), resources individuals have, be they cultural or linguistic, have different market values in different social systems. A language may have a relatively low value, if it is not the mother tongue of a group. Therefore, the social system or "linguistic field" within which a language is positioned, can be more important than the intrinsic value of the language, for all groups in any society have their own linguistic capital, which refers to "the ability to utilize appropriate norms for language use and to produce the right expressions at the right time for a particular 'linguistic market' ... there are many linguistic markets in which rare or high status forms result in profit 
for the user, and where non-standard or low-status language use is assigned a limited value" (Corson, 1993, p. 10). As in economic systems, market values of languages fluctuate from time to time and vary from place to place. However, the time and place depend on the power relations between groups, which change from one linguistic field to another, as does linguistic capital ( $\mathrm{p}$. 15). Models of multilingual education for Tibetans in China are vivid expressions of such a power relationship. For example, Tibetanisation (e.g., adopting a "pure Tibetan" model and replacing nationally practised morning exercises with traditional Tibetan dancing in schools) was more likely to occur in Tibetan-majority areas and schools where headmasters were ethnic Tibetans than in Tibetan-minority areas or schools where persons in charge were non-Tibetans (Zenz, 2010).

In the recent past, although Chinese was accorded increasing influence and authority in the TAR, different linguistic models did exist. For example, Dunzhudanzeng (2006) reported three models of bilingual education: an urban school in Lhasa used Chinese textbooks from year 1 to 6 , and the primary medium of instruction was Chinese; a county school adopted Tibetan textbooks and Tibetan as its primary medium of instruction; a rural school utilised Chinese textbooks and taught students in Chinese from year 1 to 3, then switched to Tibetan textbooks and Tibetan from year 4 to 6 . The research we conducted with students in School Basum also confirmed the existence of such a variety largely at the primary level. Partly following Dan McAdams' method of exploring stories people live by (cf. 1993, pp. 251-275), ZhiMin interviewed sixteen year 2 students of Basum. During the interviews, which lasted between thirty to sixty minutes, he requested students to divide their educational experiences up to 2011 into chapters. Each chapter focused on their learning of languages and relevant school experiences. The data collected indicated that in both junior (middle) and senior (high) secondary schools, all sixteen students, though coming from widely dispersed areas of Tibet and various socioeconomic and sociolinguistic backgrounds, ${ }^{7}$ received Chinese-medium instruction and used Chinese textbooks for all subjects, with the exception of Tibetan Language and Literature, in secondary schools. However, the students were exposed to two major models of trilingual education (sanyu jiaoyu) at the primary level, namely, Tibetan-led Model in agricultural and nomadic areas, and Chinese-led Model in towns and cities. They all commenced learning Chinese in year 1 of primary school and English in either years 1, 2, 3, or 4 of primary level.

The variety in students' experiences of multilingual education testifies, in some measure, to the choices made by different schools according to the relationship between linguistic models and the capital they confer (though implicitly). In any respect, the choice of one linguistic model over another, reflects the level of economic development, sociocultural composition, and proportion of Tibetan and Han Chinese population in an area, for such factors have an impact on the

\footnotetext{
${ }^{7}$ The primary purpose of the fieldwork was to investigate the level and nature of students' engagement with the Internet and mobile phones. In School Basum, ZhiMin first requested four classes of year 2 students (including students from both Arts and Science, Key and Ordinary classes) to fill in a survey. Based upon the survey responses, such as answers to parental education level, home access to computer, and personal ownership of mobile phones, he was able to select students from varied socioeconomic backgrounds for the interviews. In addition, ZhiMin interviewed students from both urban and rural/nomadic areas, where Tibetan and Mandarin were spoken to varying degrees. As such, he was confident of adhering appropriately to the variety principle. For a detailed description and reflection of the methods employed in the study, see Xiao (2013, Chapter 5, Section 6).
} 
language that is spoken by a particular fraction of a particular group (X. Chen, 2008, p. 89; Hong, 2007, pp. 40-42). For instance, an area with Han Chinese as the majority is likely to exhibit a linguistic pattern called min jian han (a minority people using their native minority language most of the time, only occasionally using Chinese). As the size of a minority population increases from one place to another, the pattern may gradually change to han jian min (mainstream Han Chinese using Mandarin most of the time, only occasionally using a minority language), or min jian min (one minority group, such as Luoba or Menba, using their native minority language most of the time, but occasionally using another minority language, such as Tibetan). When the Tibetan population overwhelmingly outnumbers the size of Han population, as in those Tibetan-majority areas mentioned in Zenz (2010), it is likely that the pattern will evolve to han jian min. Having examined choices of linguistic models by schools and communities, we proceed to study by what means parents arrive at such decisions.

\section{Education for upward Social Mobility: Financial, Linguistic, and Cultural Calculations}

Tibetan parents, especially those who missed out on opportunities for themselves, attach profound value to their children's education. They are often willing to send their children to schools, despite the fact that they may have to apply for loans or postpone further major family plans. This was strongly affirmed by a student (Tashi) from a nomadic background in this study. Tashi's mother once requested him to attend to the family flock during the 2010 winter vacation. He confessed that herding animals in the cold and remote plateau of Tibet was a demanding and lonely occupation, particularly in the winter. However, the family males were expected to carry out this particular task. His mother held the view that setting him up to work in such harsh conditions would make the student more earnest and keen about his studies. During the 42 minute long interview, Tashi revealed that his family attempted to apply for loans through the government in order to pay for his high school fees of about RMB 1,600 Yuan per annum (£160 GBP). He also confided that it was often tricky and complicated for such an application to be successful, if the head of his village was unwilling to act as a guarantor. Financial difficulties for most Tibetan families, probably best explains the reason behind the progression rate from middle to high schools being very low, so that even in 2009 the figure was only approximately 55\%; and also the reason why the senior secondary level was the weakest link of education in Tibet (Ma, 2011 , p. 16). As evidenced from this particular case, education was undoubtedly viewed as a means to escape poverty and hardship in rural and nomadic Tibet. The good news for students such as Tashi is that, from autumn 2011, high schools in Tibet converted to being tuition free, as did the nation-wide nine-year compulsory education programme, which does not yet cover senior secondary level, even in Beijing (Hasmath, 2011, pp. 1844-1845).

Another explanation about the value parents attach to education for their children would be the linguistic inconvenience they themselves have encountered. Today, those who are unable to speak Mandarin are more likely to be disadvantaged in urban Tibet (Badengnima, 2001, p. 96). They would be inclined to regret their inability to speak Mandarin, and as one informant in Yi Lin's study commented: "This is what I can never forget - I cannot even write a qing jia tiao (a note asking for leave) in Chinese. If I could have gone to school in those days, I would have probably been a county magistrate (xian zhang)" (2008, p. 70). That was perhaps the motive 
behind a student (Norbu) interviewed in this study, being sent to a primary school for years 4 and 5 in Chengdu, an inland city near Tibet. His well-educated parents are employed at state units, where Mandarin is the working language (formal documents usually come with a Tibetan translation). It was not surprising that they wanted their son to learn Chinese effectively and satisfactorily, and receive greater exposure to Han culture in his formative years, to improve his future prospects and career. However, the student, in fluent Mandarin, recalled, that he was so homesick in Chengdu, that he wept every day in the expensive Chinese-medium school, where there were about twenty Tibetan students from wealthier families in the TAR. Eventually, his parents came to a conclusion that he would attend a school in Tibet for his final year of primary education, where the student lamented frequent corporal punishment by Tibetan teachers because of his poor performance in Tibetan. Nevertheless, similar to the findings in Yi's study (2008, $p$. 75), students of agricultural and nomadic backgrounds in this study generally went to primary and junior secondary schools, which were located in places where the Tibetan language and culture were dominant. But the shift of the medium of instruction from Tibetan to Mandarin between primary and junior secondary levels could be one cause of significant difficulties for some students, as ascertained from the response of Tashi in this study: "Yes, it was difficult, particularly for students like us with such a poor foundation [at the primary level]. My performances suffered a great deal. Fortunately, I had a good Chinese teacher. I had many faceto-face conversations with him and he offered me a lot of support."

Although Tibetan is often viewed as less beneficial than Mandarin, some Tibetan parents do consider it necessary for their children to learn Tibetan satisfactorily. Informants in Zhu's study regarded the Tibetan language as a symbol of being Tibetan and expressed grave concerns, with reference to their incompetence in their native language (2007). In Yi's study, parents contended that if their children had a good command of Tibetan, they would be able to communicate better with locals, upon completing their higher education and returning to their home communities (2008). This explanation appeared reasonable and understandable, because it was not uncommon in the past for Tibetan students who had spent years away at inland boarding schools, to discover that they were unable to read documents written in Tibetan upon their return to Tibet (Postiglione, Jiao, \& Manlaji, 2007, p. 66). But it also appears that Tibetans have internalised the notion that, no matter how commendably and meritoriously they perform in inland China, they are expected to return to Tibet. In fact, the notion of returning to Tibet has been consciously imparted, through their curriculum and routine activities of their daily lives, to Tibetans who study in inland schools (Zhu, 2004).

The studies mentioned above were conducted outside the TAR, what does learning Tibetan in a satisfactory manner mean to those students who attend schools in Tibet then? According to Dunzhudanzeng, 92\% (22) of the teachers and parents surveyed in his study strongly disagreed with the statement that it was solely important to learn Mandarin thoroughly, $40 \%$ (19) believed that greater emphasis should be placed on Chinese in schools, only 4\% (2) thought it should be on Tibetan, and 71\% (17) of the parents opposed the use of Tibetan textbooks and the idea of teaching their children in Tibetan (2006, p. 79). However, it is rather difficult to make meaningful inferences from the findings reported in the above study due to its limitations in sampling. In Tibet, while parents generally assumed that it was disgraceful if their children were incapable of speaking Tibetan and communicating freely in the language with their fellow countrymen, the number of people who think Chinese should be the primary medium of instruction "is increasing at a remarkable rate" (Badengnima, 2009, p. 53). 
In this study, two out of the sixteen students mainly communicated in Mandarin at home with their parents, but all the parents insisted that they should be capable of communicating in Tibetan. Norbu's parents spoke poor Tibetan themselves, and hence, they desired their son to have a better and improved command of the language. For Karma, it was imperative to learn Tibetan, because people around him appeared easily distraught when he communicated partially in Chinese and partially in Tibetan with them. Moreover, Karma's teachers likewise stressed that learning Tibetan thoroughly could help boost his overall exam performance in the College Entrance Examination (Gaokao), which has very significant implications for life opportunities for countless youths across China, including Tibet.

The above cases in this study presented no indication that Tibetan was a devalued subject, as reported in Yi's study in Qinghai (2008, p. 84). Instead, both students and teachers in Basum viewed Tibetan as imparting them with a competitive advantage in the Gaokao - they simply could not afford to score low marks in Tibetan, even for those students who preferred Chinese to Tibetan. For instance, Norbu initially believed that he would not be required to take Tibetan in the Gaokao, for he had studied in a Chinese-medium school in Chengdu. But as a Tibetan, he was required to take Tibetan, regardless of his weak foundation in the subject, owing to the two years he had devoted to studying in inland China. Norbu felt obligated to take Tibetan, for the Gaokao, for his parents, and most decisively, for being a Tibetan, as stated below:

"Chinese is the easiest for me. But the most important language is still Tibetan, even though Mandarin and English are also important. My parents would be very upset if I can't speak Tibetan well. But it is becoming rather challenging, because I did not have a good foundation in the language".

\section{Promoting the Chinese-led Model and Coping with its Consequences}

Promoting a Chinese-medium education in the TAR arguably runs the risk of alienating Tibetan students, in some measure because Chinese textbooks are often said to bear little relevance to students' daily lives (Yi, 2008, p. 84), or by undermining their ethno-religious identity through the loss of their ability to read and write in Tibetan (Postiglione et al., 2007, p. 69). To what extent are those arguments well grounded and reasonable? Is it always essential for textbooks to be directly related to students' life experiences? What does it really mean to have culturally relevant textbooks? Does the learning of Chinese necessarily result in a loss of competence in Tibetan? Are Tibetans truly passive victims of state education? The answers, if any, to some of these questions, can never be straightforward and unambiguous, due to the following reasons.

Firstly, the majority of the students in School Basum in this study were Tibetan and they communicated in Tibetan with classmates and flatmates whenever possible, albeit they were primarily taught in Chinese (all subjects except for Tibetan). Indeed, when ZhiMin interviewed two or more students together, they often discussed his questions in Tibetan with one another. Nevertheless, they expressly stated that they communicated with teachers in Mandarin (Tibetan teachers in Basum were able to speak Mandarin fluently) and spoke Mandarin in class. Postiglione and associates pointed out that students in their study from different regions of Tibet had very different dialects and eventually had to communicate with one another in Chinese (2007, p. 63). In this study, this aspect appeared to be less of a problem, as Norbu opined: "[students 
from] Naqu and Ali have different dialects, but [we are] now used to them, so we understand them. They also learn our dialect upon arrival to the School, so there is no difficulty in communication [in Tibetan and Mandarin]." Consequently, according to interviewees like Chime and Chewa, they typically spoke Tibetan in daily life.

Secondly, over fifty percent of the students surveyed in this study owned mobile phones, despite the school's restrictive policy on mobile phone usage on campus. Students reported that they often called home and chatted with their parents in Tibetan. Moreover, they kept in touch with their friends studying in other schools, and the language of communication was also Tibetan. This finding largely confirmed Dunzhudanzeng's report that very few Tibetan students spoke Mandarin alone, in order to communicate with family members, although the number of families using both Tibetan and Chinese was marginally larger than that of families using only Tibetan in his study (2006). However, in precisely the same way as mobile phones in this study facilitated long-distance communication in Tibetan, televisions in Tibetan families were increasing Tibetans' exposure to Mandarin and Han Chinese culture. Over eighty percent of young Tibetans in Dunzhudanzeng's study expressed their preference for Chinese programmes, which they believed were richer in their choices of options and easier to follow (2006, p. 76). Students (Tashi, Chime, and Tara) in this study likewise expressed a similar preference.

Apart from the sociocultural impacts, the Chinese-led model's academic implications are equally open to further scrutiny. At the present time, it would be unwise to conclude that underachievement in education by the Tibetans was a result of the fact that they were compelled to learn three totally different languages simultaneously. But, it was indisputable that the students were seriously frustrated by the fact that their methods of learning were so ineffective, that they were often required to spend over forty minutes, merely to memorise a Physics theorem in Chinese (Yi, 2008, p. 80), and that their average scores in English and Mathematics could hardly reach a third of the averages in many inland schools. For instance, Zeng (2010, p. 170) reported that the average score her students achieved in 2009 was 35.6 out of 150 for English, even lower than 38.3 in 2008 and 37.9 in 2007. Their average entrance scores in English were $34.6,23.8$, and 32.1 out of 100 in 2009, 2008, and 2007 respectively. These figures indicated that the foundation of English language education in Tibet was relatively poor. Therefore, it is not unexpected that Tibetan students attending higher education institutions in inland China, often have to study harder to draw level with other students, besides having to cope with the psychological consequences of "falling", from once being a top student in high school back home in Tibet to a "laggard" in an inland university.

In view of the predicament mentioned above, teachers of English in Basum often devoted almost half of their first year undertaking remedial actions, which subsequently resulted in their failure to meet the targets set by the curriculum for the subject. An English teacher (Gao) whom ZhiMin encountered deplored the difficulty and efforts involved, in teaching the language to her students. She conveyed that she had to translate each and every word into Chinese, before she was comprehensible and understood by her students. The average score of her students in English was not much different from those established in Zeng (2010). The teacher confided that even though she set exactly the same problem sets in exam papers as those exercises students could easily find in their textbooks; her students exhibited no sign of faring better in English. Students on the other hand, perceived the subject as being despairingly challenging and demanding. Most of the students (such as Tashi, Diki, Norbu) interviewed, emphasised the point that English along 
with Mathematics, were the most difficult subjects. As Tashi revealed: "Most of them [his classmates] have simply quitted the subject". Norbu had the following to add:

"English is simply too difficult. Following it is like listening to an alien language (tian shu), I get a headache every time I see words in English. It is the most difficult subject ... the most salient problem in English is the fact that I can't remember what I learn. As a result, I become reluctant to spend too much time in memorising anything. It's too boring ... and useless. I can't use it anywhere. It's my weakest subject. The subject I feel proudest is now Chinese".

\section{Accounting for the Predicament: Who is Responsible?}

Various factors are believed to have contributed to the underachievement by Tibetan students. Firstly, Zeng (2010) affirms that English textbooks are not designed specifically for students in Tibet: the content is too difficult for students with a poor foundation to follow; and these textbooks in general ignore the fact that Tibetans have to learn English as a third language. The targets set in the curriculum are demanding. As for textbooks for other subjects, criticism has also been raised about the mere translation of Chinese editions, and the fact that these translations are often inaccurate or insensitive to regional differences that exist in Qinghai, Sichuan, and Tibet (Dunzhudanzeng, 2006, p. 78). Such criticism about textbooks, however, have to be balanced with the fact that China has gone to great lengths to produce textbooks for ethnic minorities (Hailu \& Tengxing, 2007; Postiglione, Jiao, \& Goldstein, 2011, p. 13), with textbooks now compiled in 22 different minority languages. The team responsible for the task has visited several other countries and studied the methods of multilingual education in different contexts. Nevertheless, the process of updating Tibetan textbooks is slow and expensive, and the effects of the new 2010 textbooks reforms policy, are yet to be observed. A teacher (Cao) in this study revealed that the new textbooks for all subjects, except for Chinese, were compiled by the People's Education Publication House, suggesting that learning English could become even more challenging and demanding for Tibetan students. Teacher Cao and his school responded to the reforms by conducting additional English lectures in evening sessions.

Secondly, as Zeng (2010) also reasons, it continues to be a very difficult task to employ teachers, who are capable of teaching the three languages equally well. In reality, most English teachers are Han Chinese, they largely have limited or no knowledge of Tibetan, and allegedly understand less than their Tibetan colleagues do, about Tibetan students' approaches to learning, in addition to the assertion that learning a third language through an intermediate language, is itself a different process, from learning it through a mother tongue. As noted above by the English teacher mentioned earlier, Tibetan students often encounter twofold linguistic obstacles, first through translation from English to Chinese and then from Chinese to Tibetan, when learning English. Postiglione and colleagues (2011, p. 13) deem it fundamentally necessary for students to achieve a threshold level of proficiency in Chinese as their second language; or else, using Chinese as the medium of instruction is likely to have limited or even a damaging effect on academic performance, particularly in terms of the learning of English as a third language, through their second language. Moreover, Tibetan parents and teachers in Tibet may favour Chinese as the medium of instruction from a very early age, due to the language's currency in the job market or its promise of enhanced opportunities in higher education. Postiglione and colleagues also point out that parents are not acquainted with the well-researched practice that 
students must achieve a sufficiently high level of proficiency in a second language, before they are able to satisfactorily learn subjects taught in that language (see Baker, 2011).

Nevertheless, the explanations given above assume that learning of English through Chinese is a linear process. Moreover, it is perhaps difficult in practice to define strictly what is a sufficiently high or threshold level. However, Taylor, in her $\mathrm{PhD}$ thesis, emphasised the importance of additive multilingualism, which means adding a second or third language to the repository of skills that language learners have "at no cost to the development of their first language" (2001, p. 13). According to this theory, the less can lead to more (Cummins \& Swain, 1986), which implies that Tibetan students receiving less instruction in Chinese (and more instruction in Tibetan) can learn English better than if they are solely instructed in Chinese. This is contradictory to the intuitive maximum exposure hypothesis, that the more one is exposed to a language, the better one masters that language, than if she/he is less exposed to the language (Cummins, 1996; Cummins \& Swain, 1986).

Following the then Party Secretary Hu Yaobang's visit to the TAR in May 1980, the less-is-more model was once implemented in four secondary schools of Tibet, and proved to be very successful. In 1989, Rigaze Prefectural Middle School, Shannan Prefecture Middle School No. 2, Lhasa Middle School, and Lhasa City Middle School No. 1 were selected to conduct the experiment, in which Tibetan and Chinese were two separate subjects but the primary medium of instruction was Tibetan. All teachers in the experiment were bilingual, and most textbooks, except those for Fine Arts, Music, and Physical Education, were in Tibetan. According to Zhou (2004) as well as Danzengjinmei and associates (1996), the 161 students in the experiment, all scored higher grades in exams, than their counterparts in regular Chinese-medium classes. Their performance in Mathematics was exceptionally impressive, being ten points higher than the average score of conventional class students. In 1995, 79.8\% of the students in the experiment passed the Gaokao; whereas in the conventional class, the pass rate was 39.3\% (R. Zhou, 2004, p. $65)$.

Unfortunately, the model was eventually aborted due to regional, national, and international political disturbances during that period, which witnessed a series of uprisings in Tibet, Tiananmen Pro-Democracy Demonstrations in Beijing, and the collapse of the Soviet Union. Predictably, hardliners within the Party concluded that the liberal approach to minority governance failed, and excessive freedom only denoted excessive separatist sentiments (Zenz, 2010 , p. 307). Since that time, the paramount mission of minority education has become ethnic unity and political stability (Bass, 1998, pp. 54-60). This is apparently the mission in the present day too, as publicised in school posters on the campus of Basum. However, students interviewed in this study did report on some experimental classes in the pre-high schools they once attended. For instance, Norbu divulged that his Tibetan-medium school had a Chinese class, and Cimba's Chinese-medium school had one Tibetan class. But in both cases, han yuwen (Chinese Language and Literature) and English were taught in Mandarin and zang yuwen (Tibetan Language and Literature) in Tibetan.

Thirdly, micro-interactions between educators and students also gain importance. Cummins (2000) presented an intercultural-assimilationist continuum within which most educators fall. Those with a multicultural orientation are more likely to view minority language and culture favourably, because they comprehend that minority students can "add a second language and cultural affiliation while maintaining their primary language and culture" (Cummins, 1996, p. 
147). By contrast, educators who hold an assimilationist view are inclined to request minority students to relinquish their customs and languages, before entering the school (p. 150; also mentioned in Hailu \& Tengxing, 2007). Unfortunately, according to Yi (2008), some teachers in minority schools are at the exclusionary end of the continuum or culturally insensitive, somewhat similar to the American professor and students in Yu Tianlong's study. As a non-Buddhist Chinese, Yu had to read the Dalai Lama's "religious teachings" in class, with lights turned off and candles lit up (2010, p. 1). According to Cummins' model, teachers with assimilationist sentiments would probably view Tibetan students as intellectually inferior and would tend to believe that Tibetans should be responsible for their own failure or underperformance because of their pejorative group characteristics, such as the outdated language, genetic inferiority, or parental apathy (Cummins, 1996, p. 5). In this study, one teacher did remark on the technique of raising Tibetan children, when queried to account for underachievement by Tibetan students. She pointed out, in an amused manner, that Tibetan parents, unlike Han parents, normally carry their baby on their backs during their childhood and rarely engage in conversation with the child.

Teachers with exclusionary views should unquestionably be censured for their lack of cultural knowledge or even Han chauvinism, yet the root cause of the problem appears to lie more in the structure of education, than in the factors mentioned above. Today, high schools and teachers are evaluated by their students' exam results. In order to retain a competitive edge, schools often resort to strict punitive regulations imposed upon teachers, who in turn, frequently transfer the pressure onto their students, so as to meet exam targets. Teachers, who cannot mentally cope with the pressures of teaching, simply leave their teaching jobs, for better opportunities elsewhere. In School Basum for instance, a few students (Norbu, Cimba, Indira, Tashi, and Garma) pointed out that their school seriously lacked qualified English teachers. Up to the time of the students' interviews, three teachers had already been involved in teaching English to their class. Tashi explained that the first teacher was competent at teaching the subject, but requested leave for a year because of a health problem. The second teacher paid more attention to spoken English, but quit the school for an unknown reason. Unfortunately, teachers are vulnerable to becoming scapegoats and shouldering the blame for wider issues. In Tibet, there are teachers, be they Tibetan or Han, who are at the positive end of Cummins' continuum. For instance, Norbu praised his Han teacher's fluency in Tibetan by explaining: "There was one Han teacher who spoke better Tibetan than I did. He got a master's degree in Tibetan Studies and he is now working in Gongga". Dechen also praised her English teacher: "He is good at lecturing, and every term he engages with us in different ways. The first term he may focus on reading comprehension, then the second term on building vocabulary".

Clearly, teachers like the ones mentioned above did manage to discover what they could learn from students and Tibetan communities, and how such learning could enhance their quality of instruction and enrich students' learning experiences. Chime, Dechen, and Chewa in this study also reported a positive relationship with their Han teachers. They, particularly those from Key classes, asserted that their teachers were very responsible, accomplished and qualified at what they taught, and treated them with respect. A few teachers (Cao, Gao, Xie, and Qiao) involved in this study similarly confirmed that they largely enjoyed what they were doing in Tibet. They did complain from time to time, almost certainly as many teachers do elsewhere. It is important, however, to bear in mind that their families are often thousands of miles away, their children miss them a great deal, and it is sometimes difficult to see "anything green" [perhaps due to the snow and rare patches of trees in the plateau] in school surroundings often for weeks in a stretch. 
One educator (Yang) who was informally interviewed arrived to teach in Tibet in 1983, with a highly respected degree from a prestigious normal university in inland China. He confided that when he first arrived in Bami, it was extremely problematic for him to even purchase vegetables for dinner, and when compared to the past, the roads have been repaired and are in a more desirable or significantly improved condition.

It is also important to note that the notion about teachers being culturally insensitive might actually stem from their cultural hyper-awareness. They are clearly aware that Tibetan Buddhism is a core element of Tibetan culture. But religion may perhaps be a sensitive topic in state schools. Teacher Guan advised ZhiMin to exercise caution when meeting with Tibetan teachers he should avoid discussing religion, ethnic relations, and drinking alcohol with them, as they could imbibe more alcohol than most foreigners. Nevertheless, according to Yi (2008), religion for many Tibetans has the power of cultivating moral character and nourishing one's nature (xiushen yangxing). Unfortunately, students in schools are not usually allowed to practise their religion. Yi (2008, p. 78) also contends that, those who do express their religious belief in schools, are habitually teased by other students, even by their fellow Tibetans. Teachers largely discourage students from carrying "minority things" (minzu de dongxi) into schools, for those particular practices are generally viewed as eccentric (xiqiguguai) or unhealthy (buliang).

In this study, Tashi narrated his experience in primary school. He confided that he had to repeat grades 1 to 3, when he was mysteriously afflicted with an illness in grade 3 for the first time. His mother then changed his name to his present one, and ever since the adoption of his new name, he performed commendably at school, and retained a firm position in his class, as a student in the top five. At the end of the interview, he intentionally stressed the point that: "They [his parents] are superstitious." It is worth mentioning here that, in today's ideological ranking system, Tibetans place superstition at the lowest level. They respect religious practices as customs, for which they have the highest esteem, and religion is positioned somewhere between the two (Yi, 2008, p. 80).

Finally, all of the aspects raised above appear to have overemphasised the roles educators are able to play in minority education, while overlooking the attitudes students bring to their interactions with educators. As Ogbu (1992) notes: "School success depends not only on what schools and teachers do, but also on what students do" (p. 6), and "minority children do not succeed or fail only because of what schools do or do not do, but also because of what the community does" (p. 12). It is, therefore, necessary to examine the values and attitudes that communities instil in Tibetan students and which students bring with them to schools; for the ways in which students view school education and the attitudes they develop towards educators have substantial impacts on how schools and educators react. For example, the acceptance by students and parents of one linguistic model over another may have indicated to policy makers and school leaders that the model they had initiated was indeed the correct model. This is described as the "let-the-market-decide" mentality (Postiglione et al., 2007, p. 52). But then again, attitudes and values can be skilfully directed or even manipulated by state propaganda. Today, it is not difficult to find in Tibet, and throughout the country, street billboards, banners, campus posters, magazines, TV programmes, and newspapers that promote education as a means for upward social mobility and self-empowerment. The responses of communities to this propaganda will presumably have an impact on the development of students' values and attitudes 
towards state education, and these values and attitudes in due course, will affect students' reactions, interactions, and attainment in their schools.

\section{Competence in Chinese: a Note of Caution}

Based on the 1989 experiment, would it be safe to claim that Tibetan students' performance in English could be considerably improved, perhaps if English were taught in Tibetan? Does Mandarin continue to be a problem for high school students in Tibet, in order to thoroughly grasp the knowledge of English, despite Chinese being a compulsory subject from year 1 at the primary level? In this study, most students confirmed they were able to understand lectures and Chinese language instruction was not a problem. However, two students (Tashi and Diki) attested that as regards the study of English, the struggle to comprehend was significant, and lectures consistently seemed to be never-ending. ZhiMin was convinced during his interviews that most students could easily understand what he was trying to say (in Chinese), although a few of them did show some difficulty in expressing in Chinese what they wanted to say. It is therefore logical to envisage the students facing the same or more severe problems, when they attempt to express themselves in English in the classroom, particularly when being taught through Chinese. For those students from an agricultural or nomadic area, Chinese as the medium of instruction is likely to have posed even greater challenges. In this study, students from these backgrounds (Zenji, Garma, and Dawa) gave little additional information in response to ZhiMin's questions (this might have been due to their personalities or preference of course). These students mainly relied on body language, gestures such as nodding and smiling, to confirm his statements. It is thus important to note that the level of students' proficiency in Chinese varies from person to person. In addition, the sharp shift from Tibetan to Chinese as the medium of instruction from primary to middle schools, may have long-lasting impacts on the academic performance of certain groups of students (Postiglione et al., 2011).

However, interviewees in the study did say that they could understand most lectures. We therefore have some confidence in their competence in Chinese, at least at what Cummins terms the "basic interpersonal communicative level" (in Taylor, 2001, p. 14), and this was more transparent and easier to recognise, during conversations with them. Nevertheless, this does not denote that they have skilful command of their cognitive-academic skills in Chinese, when they study subjects taught and assessed in Chinese. During ZhiMin's stay in Tibet, he was unable to collect first hand observation data of class interactions and/or documentary data about students' performances, in order to evaluate the knowledge garnered from various subjects taught in Chinese. This level of proficiency is more complex to measure and less visible than the former. Nonetheless, ZhiMin was able to learn that their average scores in Mathematics and English were unusually low. Furthermore, in Tibet, the pass level for students to enter higher education was by far lower than that in many other parts of China, and high school graduates in Science usually require only just over 200 to get into higher education (Sun, 2009). For instance, one student in Basum scored about 470 in the 2010 Gaokao and went to Peking University, although the normal requirement was a score of over 600 in most provinces. According to informants in the study, the school was awarded about a million RMB (about $£ 100,000$ GBP) because of this achievement. Basum now attracts more top-ranking students from across the autonomous region.

By mentioning the relatively low scores set for higher education in Tibet, we are not attributing Tibetan students' relative academic weakness to poor cognition skills or low aptitude levels, nor 
are we tracing the origin of their linguistic underdevelopment in English per se, and viewing it simply as an internal and individual possession of multilingual capability. Instead, we concur with Baker that there are "skills within skills" (2011, p. 7) in language ability, and that external factors, be they economic, political, or cultural, co-exist with multilingualism. We are also aware of the viewpoint in Cummins (1996) that communicative skills can develop more swiftly than cognitive-academic skills can, and the gap in time for the two skills to match can reach up to five years (Taylor, 2001, p. 14). We are therefore restrained and cautious in arriving at a conclusion, for the skills ZhiMin observed during those interviews in a café, may be qualitatively very different from the ones required in another context, such as the classroom or for an examination. We therefore maintain that students' ability in a language is multi-dimensional, and this multifaceted nature of linguistic competence will probably have broader impacts on students' overall academic performance.

\section{Pursuing the Li: towards a Conclusion}

According to Neo-Confucian scholar Zhu Xi (1130-1200) of the Southern Song dynasty (1127-1279) in China, there is a $\mathrm{Li}$ (理), principle of coherence, underlying everything in the universe (P. Bol, personal communication, Fall, 2011; see also Theodore De Bary \& Bloom, 1999, pp. 697-701). In order to thoroughly understand the things and events of the world, we must tirelessly investigate them, before we become aware of the Li (gewu qiongli 格物穷理). Is there such a Li in Tibet that defines an ideal linguistic model, a model that is conductive to meaningful, efficient, and effective learning and teaching? If there is no such Li, then what is the principle that we should adhere to, while making and/or adjusting policies related to linguistic models? Looking back at the history of Tibet, we perceive that there was no such Li underlying those linguistic models, or the Li purely persisted and endured in our minds - we, the Tibetans and the Han Chinese, followed what we felt was right for the education of Tibetans.

In the eyes of Wang Yangming (1472-1529), a Ming dynasty (1368-1644) philosopher, both Tibetans and Han Chinese in Tibet could be sages in Education. However, the problem of universal sage-hood was that the two sides did not agree on what comprised the best model. And it appears that the real sages on the stages, educators and practitioners in schools, were left out of the equation - teachers wielded little power in deciding what to teach and in which language(s) to teach, despite their knowledge and understanding of the context. We therefore argue that the Li is to be achieved by following Zhu Xi's method and allow educators in Tibetan schools to experiment as educators to find the balance between the competing aims for education in Tibet. However, it is crucial to differentiate here the Chinese notion of experimental classes or schools from that of the West as a methodology to establish causal relationships. The aforementioned experiments in 1989 adopted a Tibetan-led model. Although the students in those experiments came from diverse socioeconomic backgrounds, the teachers assigned to experimental classes, according to R. Zhou (2004), were "more proficient in both Tibetan and Chinese, more experienced in bilingual education, more organised and responsible, and have greater expertise in their specific fields" (p. 64) than those in the control groups. In addition, the experimental classes had additional morning and evening sessions during term time and extra tutorials in winter and summer vacations (p. 65). Therefore, the impressive results as cited earlier were at best misleading. In other words, the achievements could not be said to come solely from the Tibetan-led model. Without randomisation, it is difficult to rule out "outside influences" (Karlan \& Appel, 2011, "Randomized Control Trials," para. 6).

Even if the schools followed rigorous procedures in experimental design, it is still better to make moderate causal claims in education. Otherwise, one would risk making the same mistakes as Walsh McDermott and his team committed at the Navajo Reservation of Many Farms in America, where they set out to alleviate the burden of diseases for American Indians and narrow the gap in health between the natives and other groups in 1952-1962 (Jones, 2002). With good intention and great faith, the team 
successfully eradicated tuberculosis of hospitalised Navajo patients by turning every treatment into an experiment and testing the power of post-war medical technologies such as isoniazid, a new antibiotic. And yet, they failed to establish a "hospital without walls," where they aimed to cure not just the tuberculosis of hospitalised patients, but also other diseases of almost all members in the reservation ( $p$. 774). The pure biological and experimental approach failed because "medicine made many demands on patient behavior and took certain things for granted" (Jones, 2002, p. 787), for instance, windows in a house and water in a room. Recalling the mismatch of medical services to local socioeconomic conditions, McDermott later commented: "Researchers could measure the value of physician's technology, but not the value of their compassion" (p. 789), by which, he meant the trust upon which good patient-doctor relationships relied. Likewise, the good relationships between teachers and students (such as the one between Tashi and his Chinese teacher), schools and communities, or the "samaritanism" as McDermott called, are equally "intangible, unmeasurable, and outside the bounds of experiment" (p. 753). But they are vital for success in education, perhaps even more so than a correct linguistic model.

It is therefore important to recognise that the linguistic problem we have presented is not merely an educational problem. Instead, the educational reality in Tibet is also socially constructed. It is historically deep and represents diverse interests and aims for education of different groups. The models as discussed in this chapter are thus socio-politically specific - in the same way as they have been constructed, the models chosen today will influence how education develops tomorrow and how the social reality unfolds. Policy makers and interest groups in Tibet today are capable of making positive changes for tomorrow, so long as they take into consideration the fact that, their purposive actions may well have unintended consequences. In order to avoid undesirable and achieve anticipated outcomes, it is necessary to study local conditions thoroughly, and realise that models that were successful before or which function well elsewhere may not work in Tibet. In the words of Robert Merton, the "other-things-being-equal" condition may not satisfy in Tibet (1936, p. 904). But above all, it is perhaps time to change the imperious immediacy of interest in Tibet from political stability and ethnic unity to effective learning with healthy human and social development. This change, however, requires all sides to act on knowledge and wisdom rather than political opinions and ethnic sentiments.

\section{References}

Adamson, B., \& Feng, A. (2009). A comparison of trilingual education policies for ethnic minorities in China. Compare: A Journal of Comparative and International Education, 39(3), 321-333.

Badengnima. (2001). Problems Related to Bilingual Education in Tibet. Chinese Education and Society, 34(2), 91-102.

Badengnima. (2009). The Choice of Languages in Tibetan School Education Revisited. Chinese Education and Society, 41(6), 50-60.

Baker, C. (2011). Foundations of Bilingual Education and Bilingualism. Bristol, Buffalo, Toronto: Multilingual Matters.

Barnett, R. (2008). The Dalai Lama and others say that Tibetan Children have been deprived of the right to education and that Tibet has become an area of illiteracy. Is this true? In A.-M. Blondeau \& K. Buffetrille (Eds.), Authenticating Tibet: Answers to China's 100 Questions. Berkeley; Los Angeles; London: University of California Press.

Bass, C. (1998). Education in Tibet: policy and practice since 1950. London: Zed.

Berger, P., \& Luckmann, T. (1967). The social construction of reality: a treatise in the sociology of knowledge. London: Penguin.

Bourdieu, P. (1977). The economics of linguistic exchanges. Social Science Information, 16(6), 645-668. 
Chen, X. (2008). Reinforcing the achievements made in bilingual education in Xinjiang and examining English language education for minority peoples (Gonggu Xinjiang shuangyu jiaoyu chengguo, tansuo shaoshu minzu yingyu jiaoxue) Assessment Weekly (Kaoshi Zhoukang), 31, 89-91.

Chen, Y., \& Postiglione, G. A. (2009). Muslim Uyghur Students in a Dislocated Chinese Boarding School: Bonding Social Capital as a Response to Ethnic Integration. Race/Ethnicity: Multidisciplinary Global Perspectives, 2(2), 287-309.

Cobbey, H. (2007). Challenges and Prospects of Minority Bilingual Education in China - An Analysis of Four Projects. In A. Feng (Ed.), Bilingual education in China: practices, politics, and concepts. Clevedon: Multilingual Matters.

Corson, D. (1993). Language, minority education and gender: linking social injustice and power. Clevedon, England; Toronto, ON: Multilingual Matters/OISE Press.

Cummins, J. (1996). Negotiating identities: education for empowerment in a diverse society (Expanded ed.). Stoke: Trentham Books Ltd.

Cummins, J. (2000). Language, Power and Pedagogy: bilingual children in the crossfire. Clevedon: Multilingual Matters.

Cummins, J., \& Swain, M. (1986). Bilingualism in education: Aspects of theory, research and practice. London: Longman.

Danzengjinmei, Baimaciren, \& Suolangdunzhu. (1996). Xizang shuangyu jiaoyu de shijian yu tansuo (Bilingual education in Tibet: practices and experiments). Xizang Yanjiu (Tibet Studies), 1, 21-28.

Dunzhudanzeng. (2006). A study of bilingual education in Tibetan primary schools (Xizang xiaoxue shuangyu jiaoyu yanjiu). Tibetan Studies, 2, 73-82.

Farmer, P. (2005). Pathologies of Power: Health, Human Rights, and the New War on the Poor: with a New Preface by the Author. Berkeley: University of California Press.

Feng, A., \& Sunuodula, M. (2009). Analysing language education policy for China's minority groups in its entirety. International Journal of Bilingual Eeducation and Bilingualism, 12(6), 685-704.

Goldstein, M. (1997). The snow lion and the dragon: China, Tibet, and the Dalai Lama. Berkeley; London: University of California Press.

Goldstein, M., Childs, G., \& Puchung Wangdui. (2010). Beijing's "People First" Development Initiative for the Tibet Autonomous Region's Rural Sector - A Case Study from the Shigatse Area. The China Journal(63), 57-76.

Goldstein, M., Jiao, B., Beall, C., \& Tsering, P. (2003). Development and change in rural Tibet: problems and adaptations. Asian Survey, 43(5), 758-779.

Hailu, \& Tengxing. (2007). A reflection upon and recall of minority education policies in the People's Republic of China: an interview with an educational anthropologist (Xinzhongguo minzu jiaoyu zhengce de huigu yu sikao: jiaoyu renleixue xuezhe fangtan lu). Journal of Inner Mongolia Normal University (Educational Science) [neimenggu daxue xuebao (jiaoyu kexue ban)], 20(7), 17-21.

Hannum, E. (2003). Poverty and Basic Education in Rural China: Villages, Households, and Girls' and Boys' Enrollment. Comparative Education Review, 47(2), 141-159.

Hasmath, R. (2011). The education of ethnic minorities in Beijing. Ethnic and Racial Studies, 34(11), 1835-1854. doi: 10.1080/01419870.2011.553238

Hong, Y. (2007). Constructing a bilingual teaching model based on the relations of different languages (Goujian butong yuyan guanxi xia de shuangyu jiaoxue moshi). Journal of Research on Education for Ethnic Minorities (Minzu Jiaoyu Yanjiu), 18(83), 39-44.

Huang, B. (2007). Teachers' Perceptions of Chinese-English Bilingual Teaching in Guangxi. In A. Feng (Ed.), Bilingual education in China: practices, politics, and concepts. Clevedon: Multilingual Matters. 
Johnson, B. (2000). The politics, policies, and practices in linguistic minority education in the People's Republic of China: the case of Tibet. International Journal of Educational Research, 33(6), 593600. doi: http://dx.doi.org/10.1016/S0883-0355(00)00037-9

Jones, D. (2002). The Health Care Experiments at Many Farms: The Navajo, Tuberculosis, and the Limits of Modern Medicine, 1952-1962. Bulletin of the history of medicine, 76(4), 749-790. doi: $10.1353 / \mathrm{bhm} .2002 .0186$

Karlan, D., \& Appel, J. (2011). More than good intentions: how a new economics is helping to solve global poverty (Kindle ed.). New York: Dutton.

Liao, Z. (2008). Cong Shuzi Kan Xizang (Investigating Tibet through numbers). Xuexi Yuekan (Learning Monthly), 5(403), 19-20.

Lu, A. (2005). A research report on basic education in agricultural Tibet. In L. Wang \& L. Zhu (Eds.), Marketisation and Basic Public Service: a case study in Tibet. Beijing: Nationalities Publication House (Minzu Chuban She).

Ma, R. (2011). Bilingual Education and Social Development in Tibet (Xizang Shehui Fazhan Yu Shuangyu Jiaoyu). China Tibetology, 2, 1-34.

McAdams, D. P. (1993). The stories we live by: personal myths and the making of the self. New York: Guilford Press.

Merton, R. K. (1936). The Unanticipated Consequences of Purposive Social Action. American Sociological Review, 1(6), 894-904. doi: 10.2307/2084615

Ogbu, J. (1992). Understanding cultural diversity and learning. Educational Researcher, 21(8), 5-14+24.

Postiglione, G. A. (2008). Making Tibetans in China: the educational challenges of harmonious multiculturalism. Educational Review, 60(1), 1-20.

Postiglione, G. A., Jiao, B., \& Goldstein, M. (2011). Education in the Tibetan Autonomous Region: Policies and Practices in Rural and Nomadic Communities. In J. Ryan (Ed.), Education reform in China: changing concepts, contexts and practices. Abingdon, Oxon: Routledge.

Postiglione, G. A., Jiao, B., \& Manlaji. (2007). Language in Tibetan Education: the Case of the Neidiban. In A. Feng (Ed.), Bilingual education in China: practices, policies, and concepts. Clevedon: Multilingual Matters.

Steel, D., Alton, D., Wyatt, D., \& Gray, J. (2009). Tibet: Breaking The Deadlock. London: All Party Parliamentary China Group.

Sun, S. (2009). A Year in Tibet. London: Harper Perennial.

Taylor, S. (2001). Trilingualism by design?: an investigation into the educational experience of Kurdish children schooled in Denmark. (PhD), University of Toronto, Toronto.

Theodore De Bary, W., \& Bloom, I. (1999). Sources of Chinese Tradition: from earliest times to 1600 (2nd ed. Vol. One). New York: Columbia University Press.

Wan, M., \& Zhang, S. (2007). Research and Practice of Tibetan-Chinese Bilingual Education. In A. Feng (Ed.), Bilingual education in China: practices, politics, and concepts. Clevedon: Multilingual Matters.

White, J. (1982). The aims of education restated. London: Routledge \& Kegan Paul.

Xiao, Z. (2013). "You are too out!": a mixed methods approach to the study of "digital divides" in three Chinese senior secondary schools. (PhD in Education), Durham University, Durham.

Yi, L. (2008). Cultural Exclusion in China: State Education, Social Mobility and Cultural Difference. Oxford, New York: Routledge.

$\mathrm{Yu}, \mathrm{T}$. (2010). Deconstructing the master narrative on Tibet: lessons for education. Discourse: Studies in the Cultural Politics of Education, 31(1), 1-15. doi: 10.1080/01596300903465385

Zeng, H. (2010). An analysis of the challenges in the teaching and learning of high school English in Tibet and the strategies to confront them: a case study in Linzhi (Xizang zangzu gaozhongsheng yingyu 
jiaoxue de nandian fenxi ji yingdui celve). Journal of Shanxi University (Shanxi daxue xuebao), 37, 170-172.

Zenz, A. (2010). Beyond Assimilation: The Tibetanisation of Tibetan Education in Qinghai. Inner Asia, 12(2), 293-315. doi: 10.1163/000000010794983478

Zhou, R. (2004). On Bilingual Education in Tibet. Journal of Tibet University, 19(4), 62-67.

Zhou, W. (2003). Xizang de yuyan he shehui [Tibetan language and society]. Beijing: China Tibetology.

Zhou, W., \& Gesang Jiancun. (2004). Work on the Tibetan language and literature in Tibet (Xizang de Zang Yuwen Gongzuo). Beijing: China Tibetology (Zhongguo ZangXue).

Zhu, Z. (2004). State Schooling and Ethnic Identity: a study of an inland Tibet middle school in the People's Republic of China. (PhD), The University of Hong Kong, Hong Kong.

Zhu, Z. (2007). State Schooling and Ethnic Identity: the politics of a Tibetan Neidi Secondary School in China. Plymouth: Lexington Books.

Zhu, Z. (2008). Reflections on Basic Education Under the "Three Guarantees" Policy in Tibet's Pastoral Districts. Chinese Education and Society, 41(1), 44-50. 